\title{
ADAPTAR, ADEQUAR, DIFERENCIAR: reflexões a partir das políticas curriculares para o público-alvo da Educação Especial
}

\author{
Yasmin Ramos Pires ${ }^{1}$ \\ Geovana Mendonça Lunardi Mendes ${ }^{2}$
}

Resumo: O presente artigo tem como objetivo investigar como no conjunto de documentos que estamos nomeando como políticas curriculares, especialmente cinco textos curriculares criados pós Política Nacional de Educação Especial na perspectiva da Educação Inclusiva, em 2008, vêm evidenciando movimentos curriculares como adaptação, adequação ou diferenciação curricular como formas de inclusão do público-alvo da Educação Especial. O desenvolvimento metodológico deste trabalho deu-se por meio de pesquisa documental, investigando-se alguns dos textos políticos se referem a estes movimentos e que advogam na defesa de um determinado termo como processo de inclusão. Esta pesquisa fez parte do projeto intitulado "Escolarização de alunos com deficiência intelectual: políticas públicas, processos cognitivos e avaliação da aprendizagem" que procurou investigar as formas de escolarização dos alunos com deficiência intelectual inseridos na sala de aula regular e no Atendimento Educacional Especializado. Essa discussão, portanto, é um aprofundamento de questões curriculares presentes no projeto. A análise das políticas curriculares realizadas neste artigo identificou que poucas são as evidências dos movimentos curriculares de adaptação, flexibilização e/ou diferenciação curricular como possibilidades para a inclusão dos alunos público-alvo da Educação Especial. De acordo com a leitura atenta, por meio das políticas curriculares pesquisadas, os tipos de movimentos curriculares aqui conceituados não são representados como formas efetivas de possibilidade de trabalho pedagógico para o público-alvo da Educação Especial.

Palavras-chave: Currículo. Adaptação, adequação e diferenciação curricular.
Resumen: El presente artículo tiene como objetivo investigar cómo en el conjunto de documentos que da derecho como políticas curriculares, especialmente cinco textos curriculares creados después de la Política Nacional de Educación Especial en la perspectiva de la Educación Inclusiva, en 2008, vienen evidenciando movimientos curriculares como adaptación, adecuación o diferenciación curricular como formas de inclusión del público objetivo de la Educación Especial. El desarrollo metodológico de este trabajo se dio por medio de investigación documental, investigando algunos de los textos políticos se refieren a estos movimientos y que abogan en la defensa de un determinado término como proceso de inclusión. Esta investigación formó parte del proyecto titulado "Escolarización de alumnos con discapacidad intelectual: políticas públicas, procesos cognitivos y evaluación del aprendizaje" que buscó investigar las formas de escolarización de los alumnos con discapacidad intelectual insertados en el aula regular y en la Atención Educativa Especializada. Esta discusión, por lo tanto, es una profundización de cuestiones curriculares presentes en el proyecto. El análisis de las políticas curriculares realizadas en este artículo identificó que pocas son las evidencias de los movimientos curriculares de adaptación, flexibilización y / o diferenciación curricular como posibilidades para la inclusión de los alumnos público objetivo de la Educación Especial. De acuerdo con la lectura atenta, por medio de las políticas curriculares investigadas, los tipos de movimientos curriculares aquí conceptuados no son representados como formas efectivas de posibilidad de trabajo pedagógico para el público objetivo de la Educación Especial.

Palabras-clave: Currículo. Adaptación, adecuación y diferenciación curricular.

\footnotetext{
${ }_{1}$ Mestranda em Educação pela Universidade do Estado de Santa Catarina. Professora da Rede Municipal de Florianópolis. E-mail: yasminpires@hotmail.com. ORCID: http://orcid.org/0000-0002-4781-1076.

2 Doutorado em Educação: História, Política, Sociedade pela Pontifícia Universidade Católica de São Paulo . Professora do Departamento de Pedagogia e do Programa de Pós-Graduação em Educação da Universidade do Estado de Santa Catarina. E-mail: geolunardi@gmail.com. ORCID: http://orcid.org/0000-0002-3405-9639.
} 


\section{ARGUMENTOS INICIAIS}

O presente artigo tem como objetivo discutir como as políticas curriculares voltadas para o público-alvo da Educação Especial, entre os anos de 2008 a 2016, evidenciam a necessidade de movimentos curriculares como adaptação, flexibilização e/ou diferenciação curricular.

O desenvolvimento metodológico deste trabalho deu-se por meio de pesquisa documental, a partir das políticas curriculares direcionadas para a Educação Especial na perspectiva inclusiva de 2008 a 2016, além de discussão baseada em autores que auxiliam na compreensão do currículo para o aluno com deficiência intelectual e das políticas de Educação Especial para estes sujeitos (LUNARDI-MENDES, SILVA, 2014; MESQUITA, 2009, 2010; ROLDÃO, 2003, e outros).

Este recorte de pesquisa fez parte de um projeto intitulado "Escolarização de alunos com deficiência intelectual: políticas públicas, processos cognitivos e avaliação da aprendizagem"3 que procurou investigar as formas de escolarização dos alunos com deficiência intelectual inseridos na sala de aula regular e nas salas de recursos Multifuncionais por meio do Atendimento Educacional Especializado. Este artigo elucida, portanto, o recorte e aprofundamento das discussões realizadas no projeto, por meio da análise das políticas da Educação Especial na perspectiva Inclusiva entendendo o movimento, por meio das políticas curriculares, dos temas referentes a adaptação, adequação ou diferenciação curricular.

Inicialmente, apresentamos uma análise conceitual dos termos adaptação, adequação e eiferenciação curricular no contexto das propostas de inclusão escolar no âmbito da Educação Especial, para evidenciar de que forma os conceitos são trabalhados por diferentes autores da área da Educação.

$\mathrm{Na}$ segunda parte do texto, apresentamos os resultados decorrentes das análises realizadas a partir das políticas curriculares brasileiras estudadas, compreendidas entre 2008 a 2016, pós Política da Educação Especial na Perspectiva da Educação Inclusiva (PNEPEEI, BRASIL, 2008).

Ainda que de maneira ensaística, esperamos que nossas análises possam contribuir para esta temática ainda tão difusa e emaranhado no campo da Educação Especial.

\section{ADAPTAR, ADEQUAR, DIFERENCIAR: do que estamos falando?}

Modificar o currículo para atender as necessidades específicas dos alunos inseridos na escola regular como público-alvo da educação especial, parecem ser uma "tônica" recorrente nos discursos e textos políticos voltados para a inclusão desta população.

As defesas em torno da inclusão escolar deste público, advogam na defesa da modificação do currículo, da sala de aula, do espaço escolar, e dos processos de ensino.

Nesse sentindo, durante muito tempo, o termo mais presente na literatura e em algumas legislações brasileiras (anterior à 2008) foi o termo "adaptação" escolar e/ou curricular.

No Brasil, como referência ao termo adaptação curricular, observamos a incidência nas pesquisas acadêmicas brasileiras do "Projeto Escola Viva - Adaptações Curriculares" (ARANHA, 2005). O projeto Escola Viva foi um projeto orientado pela Secretaria de Educação Especial do Ministério da Educação e Cultura (MEC), a fim de dispor aos professores alguns materiais que auxiliassem nas formações para o trabalho sobre educação inclusiva.

\footnotetext{
${ }^{3}$ Consiste em um projeto em rede, realizado pela Universidade do Estado de Santa Catarina (UDESC), Universidade do Vale do Itajaí (Univali) e Universidade Federal Rural do Rio de Janeiro (UFFRJ). Foi um projeto financiado pela Coordenadoria de Aperfeiçoamento de Pessoal de Nível Superior (CAPES), com o apoio das respectivas universidades. Foi coordenado pelas professoras Dra. Geovana Mendonça Lunardi Mendes, Dra. Márcia Denise Pletsch e Dra. Regina Célia Linhares Hostins.
} 
O projeto elaborou cinco cartilhas e dois vídeos, que tratam sobre a história da Educação Especial e Inclusiva, até a possibilidade de construir a inclusão no espaço escolar. Dentro dessas duas cartilhas, duas destacaram-se por tratar de adaptações curriculares na sala de aula. Estas duas cartilhas orientam os professores no tipo de adaptação que eles podem realizar a partir de determinadas propostas em sala de aula. Além disso, a adaptação curricular no Brasil é entendida a partir de duas perspectivas: adaptações curriculares de pequeno porte e adaptações curriculares de grande porte. No sentido mais amplo, de acordo com Aranha (2005, p. 8),

[...] Adaptações Curriculares, portanto, são respostas educativas que devem ser dadas pelo sistema educacional, de forma a favorecer a todos os alunos e, dentre estes, os que apresentam necessidades educacionais especiais: ao acesso ao currículo, a participação integral, efetiva e bem-sucedida em uma programação escolar tão comum quanto possível, a consideração e o atendimento de suas peculiaridades e necessidades especiais no processo de elaboração: do plano municipal de educação, no projeto pedagógico da unidade escolar, do plano de ensino professor.

Ainda no termo adaptação curricular, há distinção das de pequeno porte para as de grande porte. Segundo Aranha (2005, p. 9), as adaptações curriculares de pequeno porte dizem respeito a "modificações menores, de competência específica do professor. Elas constituem pequenos ajustes nas ações planejadas a serem desenvolvidas no contexto da sala de aula.". Na cartilha, fica explicitado ainda que as adaptações de pequeno porte devem ser realizadas a nível de objetivos, de conteúdos, de método de ensino e organização didática, do processo de avaliação e na temporalidade do processo de ensino e aprendizagem.

Entendemos as adaptações curriculares de pequeno porte, conforme sugerido pela autora, aquelas que são realizadas nas atividades de sala de aula, sem mudança curricular geral. Já as de grande porte são entendidas como

[...] ações que são da competência e atribuição das instâncias político-administrativas superiores, já que exigem modificações que envolvem ações de natureza política, administrativa, financeira, burocrática, etc. (ARANHA, 2005, p. 9).

Ainda referente a adaptação, encontramos enquanto referência teórica, porém no campo da Psicologia a produção "Adaptação Escolar" de autoria de Maria Helena Novaes. Segundo Novaes (2002), o conceito de adaptação, construído pela psicologia, é entendido a partir das condições do meio à que o sujeito está inserido. Segundo a autora,

Adaptação consiste, pois, num processo que leva o indivíduo a dominar as exigências do meio, através de diversas modalidades, havendo sempre expectativas em torno das suas formas de adaptação nos diversos sistemas de relações (NOVAES, 2002, p. 18)

A autora entende que a adaptação escolar não pode consistir apenas na mudança das atividades dos alunos, mas na forma como a escola pensa as propostas para todos os sujeitos que compõe o espaço escolar. De acordo Novaes (2002, p. 9),

[...] "adaptação escolar" é, na maioria das vezes, só considerada em relação aos alunos, não se levando em conta a reciprocidade implícita do processo e a sua repercussão nos comportamentos dos professores e no clima psicológico 
da escola, sem se cogitar sequer em considerar os condicionamentos contextuais, situacionais e injuncionais inerentes à interação social.

Para a autora, não apenas os alunos precisam de adaptação para o meio que estão inseridos, mas todos os que fazem parte do contexto, entendendo que todos devem se adaptar a novas situações/modificações do dia-a-dia.

$\mathrm{Na}$ área da Educação, alguns autores procuram evidenciar em suas pesquisas científicas o currículo para o aluno com deficiência, observando os tipos de práticas para o público-alvo da Educação Especial e conceituando também termos com adaptar, diferenciar e flexibilizar referente a questões curriculares.

Moscardini (2011), por exemplo, observou que há um distanciamento das propostas da sala de aula regular de ensino do Atendimento Educacional Especializado (AEE), e que as propostas eram fragmentadas e não proporcionavam

Iniciativas que procurem promover a adaptação curricular necessária para que esse público possa realizar as tarefas propostas tendo as suas singularidades respeitadas. (MOSCARDINI, 2011, p. 8).

O autor entende que a adaptação curricular deve ser tomada a partir das tarefas que são propostas pelo professor, ou seja, modificando o currículo da sala de aula, das estratégias realizadas pelo professor para que o aluno possa conseguir alcançar o objetivo proposto.

Na pesquisa realizada por Vieira (2012), ficou evidenciado que as adaptações/flexibilizações (aqui tomadas como sinônimo) não podem ser tomadas como uma escolha ruim por parte da escola, mas como possibilidade de aprendizagem para os alunos com deficiência e transtornos globais do desenvolvimento na escola.

Verificamos que na pesquisa de Vieira (2012), o termo adaptação curricular aparece vinculado ao termo adequação/flexibilização curricular. Para o autor, conceitualmente exemplificando, "flexibilizar ou adequar, nesse sentido, significa superar obstáculos que buscam dificultar o acesso ao conhecimento" (VIEIRA, 2012, p. 298).

Para Boer (2012), o termo adequação curricular é sugerido para se tratar de propostas para alunos com deficiência. A autora advoga em defesa do uso "adequação curricular" e justifica que não é possível continuar o uso do termo "adaptação curricular" por entende-lo de como um conceito obsoleto e com significado voltado para a repetição da história de segregação do aluno com deficiência no espaço escolar. Para a autora, citando Heredero (2011),

[...] Segundo Heredero (2011), adaptação curricular tem a ver com os conceitos da antiga escola, dividida e segregadora, nos termos de adaptar alguma coisa; neste caso, o currículo, para que possa atender os alunos com deficiência. Por um lado, poderia se afastar do currículo ordinário que todos os alunos seguem. Por outro lado, adequação curricular é um termo da escola inclusiva contemporânea, que objetiva a adequação do currículo para todos os estudantes da série na qual o aluno com deficiência esteja inserido, para que esse aluno possa acompanhar as aulas e desenvolver os mesmos conteúdos que o restante da sala, de acordo com suas respectivas habilidades. (BOER, 2012, p. 26, grifo nosso).

A autora, além de defender o uso de adequação curricular, também realiza a explicação de adequação curricular por meio de políticas educacionais brasileiras dos anos 1971 a 2009 e explica o conceito por meio dos seguintes autores (CARVALHO, 2008; ZANATA, 2004; HEREDERO, 2010; GARCIA, 2009; SACRISTAN, 2000; FIERRO, 2004; OLIVEIRA, 2008). 
Boer (2012) verificou que a formação para os professores por meio da ação de construção de um plano de adequação curricular possibilitou a "ampliação do plano de adequação curricular a outros educandos que não possuíam deficiência, mas sim dificuldades de aprendizagem" (BOER, 2012, p. 9). A autora salienta que o importante do trabalho escolar para inclusão dos alunos com deficiência é o trabalho colaborativo, pois a partir das experiências dos professores, das suas formações, etc., é possível construir recursos e estratégias para a inclusão do aluno com deficiência no espaço escolar, por meio de diálogo e da troca de experiências.

Outras referências por meio do levantamento bibliográfico foram possíveis de identificar por meio do cruzamento dos conceitos diferenciação, flexibilização, adequação e adaptação curricular (LOBO, 2011; MELO, 2008; VALERA, 2015; MESQUITA, 2015; SANTOS, 2015; FLORO, 2016; CORREIA, 2016; MESQUITA, 2013). Essas pesquisas procuram mostrar a produção e as práticas curriculares para os alunos com deficiência e quais possibilidades as escolas encontram para incluir os alunos com deficiência na sala de aula regular ou no AEE (que tipo de práticas, de estratégias, de recursos, etc.). ${ }^{4}$

Em se tratando de diferenciação curricular, conceituamos a partir das contribuições de Roldão (2003) e Pacheco (2008). Segundo os estudos realizados por Roldão (2003, p. 58)

A diferenciação curricular que procuramos conceptualizar há de situar-se no plano da acção curricular inteligente da escola e dos professores, intencional e informada por conhecimento científico adequado, para, partindo de onde o aluno está (...), poder orientar adequadamente e com sucesso a construção diferenciada da aprendizagem de cada um, relativamente ao currículo comum, visando, na medida máxima possível, o melhor acesso de todos à integração plena na sociedade a que pertencem e de que são desejavelmente actores activo.

De acordo com a autora, o modo errôneo como vêm se conceituando o termo diferenciação curricular, dentro de um currículo formulado a partir de questões técnicas e tradicionais, auxilia na manutenção de uma lógica de diferenciação social, econômica e cultural negativa. Neste movimento de diferenciação negativa, segundo Roldão (2003), os alunos com menor poder econômico, acabam tendo um ensino voltado ao trabalho pouco qualificado. Para os alunos com deficiência, a escola se vê incapaz de prestar o atendimento integral e acaba responsabilizando outras instituições para sua educação ou por vezes, responsabilizando aos cuidados da própria família. A autora afirma que é preciso reconstruir o conceito de diferenciação curricular e tirá-lo do nível da discriminação.

Para Pacheco (2008, p. 182)

A diferenciação curricular é um conceito que representa, essencialmente, mudanças na metodologia e na avaliação, pressupondo que os alunos têm um mesmo percurso nas suas opções, mas que uns precisam de seguir caminhos diferentes para que todos possam atingir o sucesso educativo.

O autor realiza uma análise por meio de políticas internacional sobre a Educação e identifica que em grande parte dos documentos a tônica é ressaltar o direito a educação para todos os cidadãos. Nesse caso, o Estado deve garantir o direito de que todas as pessoas tenham acesso ao conhecimento. Pacheco (2008) reflete que os acordos internacionais com vistas a Educação influenciam de maneira significativa os contextos locais na criação de seus currículos escolares.

\footnotetext{
${ }^{4}$ Para identificar outras possibilidades do entendimento de adaptação, flexibilização, adequação ou diferenciação curricular, analisar estes autores.
} 
De acordo com o autor, as políticas podem ser iguais no sentido de garantir os direitos aos cidadãos, mas as escolas devem possuir autonomia para construir seus projetos curriculares e atenderem seus alunos com estratégias de ensino diferenciadas, sem que isso se torne um motivo de discriminação e segmentação dos alunos.

Por meio da discussão teórica aqui iniciada e que não se esgota, procuraremos refletir de que forma as políticas curriculares dão conta de apresentar os movimentos curriculares aqui citados como uma das formas de inclusão do público-alvo da Educação Especial no sistema de ensino comum.

\section{POLÍTICAS CURRICULARES DE EDUCAÇÃO ESPECIAL NA PERSPECTIVA INCLUSIVA: em foco a adaptação, adequação e diferenciação}

São diversos os modos de compreendermos o que consideramos políticas curriculares. No âmbito deste texto, optamos por usar a compreensão explicitada por Gimeno Sacristán (2000) e que orienta muito bem nossas escolhas. Nesse sentido, a política curricular pode ser compreendida como

Um aspecto específico da política educativa, que estabelece a forma de selecionar, ordenar e mudar o currículo dentro do sistema educativo, tornando claro o poder e a autonomia que diferentes agentes têm sobre ele, intervindo dessa forma, na distribuição do conhecimento dentro do sistema escolar e incidindo na prática educativa, enquanto apresenta o currículo a seus consumidores, ordena seus conteúdos e códigos de diferentes tipos. (SACRISTÁN, 2000, p. 109).

Considerando a importância da PNEPEEI (BRASIL, 2008) e os impactos dessa política nos demais documentos norteadores da Educação Especial, realizamos a seleção dos documentos brasileiros da Educação Especial, entre os anos 2008 a 2016, a fim de entendermos como os conceitos discutidos anteriormente são ressaltados nas políticas curriculares destinadas ao público-alvo da inclusão.

Vale ressaltar, no entanto, que apesar deste recorte temporal, anterior as datas mencionadas, as políticas educacionais brasileiras já evidenciavam políticas de currículo voltadas a inclusão escolar do público-alvo da Educação Especial indicando movimentos curriculares de natureza adaptativa. Por exemplo, os Parâmetros Curriculares Nacionais (PCNs) - adaptações curriculares: atendimento às pessoas com necessidades educacionais especiais já nos anos de 1998, explicitavam a necessidade de modificação do currículo. Segundo Mesquita (2010, p. 311), esses parâmetros foram

[...] elaborados em 1998 pela Secretaria de Ensino Fundamental em parceria com a Secretaria de Educação Especial [...]. O documento foi elaborado com base no reconhecimento da diversidade existente na população escolar e na necessidade de respeitar e atender a essa diversidade.

No campo da Educação Especial, o conceito e o termo adaptação curricular para o aluno com deficiência não é uma novidade no Brasil. É importante salientar que grande parte das políticas construídas para esse fim, entre os anos 1990 até os dias atuais são decorrentes de acordos mundiais, tanto os PCNs (BRASIL, 1998) quanto à PNEPEEI (BRASIL, 2008).

Exemplos podem ser dados a partir dos objetivos de três importantes documentos internacionais: a Declaração Mundial sobre Educação para todos (WCEFA, 1990), a Declaração de Salamanca (UNESCO, 1994) e a Convenção Internacional sobre os direitos das pessoas com deficiência (ONU, 2006), acordos em que o Brasil é signatário. Estes documentos têm influenciado países como o Brasil na instituição das políticas educativas na perspectiva inclusiva.

A Declaração Mundial sobre Educação para Todos (WCEFA, 1990) é um documento que tem como foco traçar objetivos para uma educação universal, que atenda às necessidades básicas de aprendizagem dos estudantes. A justificativa para a criação deste acordo está amparada em índices de 
falta de acesso a escolarização de muitas crianças e adolescentes, falta de acesso ao conhecimento pela população de um modo geral e a preocupação com o analfabetismo funcional. Por meio deste documento é possível inferir que a preocupação internacional está voltada ao acesso à educação a todos, entendendo a educação como meio de alteração da realidade econômica e social, dado o momento histórico de constante transformações em que o documento foi criado (década de 90 do século passado). No que diz respeito as consequências no Brasil, entendemos que este acordo fortaleceu e propiciou, de maneira significativa, o crescimento das políticas públicas de universalização da educação no país.

Na Declaração de Salamanca (UNESCO, 1994) constatamos que a preocupação central do acordo está focada no direito e acesso à educação para o público-alvo da educação especial. $O$ texto sugere formação para trabalhar com esse público, espaço e tecnologias adequadas, além de um currículo que corresponda às necessidades dos educandos, apoio financeiro dos governos e instituições nacionais e internacionais para propiciar uma educação de qualidade. O documento responsabiliza não só o governo para a educação deste público, mas também família, escola, comunidade, etc. Esta declaração, para o Brasil, contribuiu para o comprometimento do país com a escolarização dos alunos público-alvo da educação especial, prioritariamente na escola de ensino comum.

O acordo mediado pela Convenção internacional sobre os direitos das pessoas com deficiência (ONU, 2006) aponta a preocupação da comunidade internacional em traçar objetivos que garantam, especificamente, o acesso e permanência das pessoas com deficiência à Educação. Diferentemente da Declaração de Salamanca, que apresenta o acordo para o público-alvo da educação especial, este acordo se detém ao público das pessoas com deficiência.

Cabe destacar que esses três acordos se configuram em textos políticos, de âmbito internacional, pensados para a Educação e que influenciam na criação de políticas nacionais, que consequentemente exercem influências nas criações dos textos políticos curriculares brasileiros.

A partir de 2008, no Brasil, outros textos políticos foram instituídos, para além dos parâmetros de 1998, e que se configuram em uma reescrita dos acordos traçados anteriormente (que prometem a garantia da inclusão dos alunos no espaço escolar). Nos detemos, para este artigo, em cinco textos políticos curriculares: a PNEPEEI, 2008; o Decreto n. ${ }^{\circ}$ 6.949, de 25 de agosto de 2009; Resolução n. ${ }^{\circ}$ 4, de 02 de outubro, de 2009; Resolução CNE/CEB n. ${ }^{\circ} 4$, de 13 de julho, de 2010; Decreto n. 7.611 , de 17 de novembro, de 2011.

Trabalhamos objetivamente a partir destes textos políticas por terem sido criados pós PNEPEEI (BRASIL, 2008) e por já representarem, em grande medida, textos que contém influência da Política Nacional instituída em 2008, que será melhor explicitada nos parágrafos seguintes. Dentro desses documentos, procuramos analisar de que forma a inclusão escolar é evidenciada no documento e se ela é relacionada aos movimentos de adaptação/adequação/flexibilização ou diferenciação curricular para o público-alvo da Educação Especial.

A PNEPEEI (BRASIL, 2008) realiza um histórico da Educação Especial e seus marcos, além de explicitar seus objetivos, seu público-alvo e as diretrizes para a consolidação da política. Referente ao ensino na sala de aula regular, observamos menções diretas na relação com o $\mathrm{AEE}$, não podendo o $\mathrm{AEE}$ ser substitutivo ao ensino da sala regular. Segundo a PNEPEEI (BRASIL, 2008, p. 11),

As atividades desenvolvidas no atendimento educacional especializado diferenciam-se daquelas realizadas na sala de aula comum, não sendo substitutivas à escolarização. Esse atendimento complementa e/ou suplementa a formação dos estudantes com vistas à autonomia e independência na escola e fora dela. 
Ainda de acordo com a Política, o ensino no AEE deve estar em consonância com as propostas pedagógicas do ensino comum. A política, no entanto, não indica em suas diretrizes como essa relação pode ser feita, explicitando apenas que os sistemas de ensino comum devem se organizar para oferecer aos estudantes

[...] as condições de acesso aos espaços, aos recursos pedagógicos e à comunicação que favoreçam a promoção da aprendizagem e a valorização das diferenças, de forma a atender as necessidades educacionais de todos os estudantes. A acessibilidade deve ser assegurada mediante a eliminação de barreiras arquitetônicas, urbanísticas, na edificação - incluindo instalações, equipamentos e mobiliários - e nos transportes escolares, bem como as barreiras nas comunicações e informações. (PNEEPEI, 2008, p. 13).

Apesar de não fazer menção a adaptação de atividade e/ou curricular, inferimos que por meio da especificação de que deve ser proporcionado aos estudantes recursos pedagógicos que favoreçam a promoção de sua aprendizagem e a valorização das diferenças, além de garantir acessibilidade e eliminar barreiras de comunicações e informações, fica implicitamente sugerido que algumas atitudes devem ser tomadas para que as barreiras possam ser eliminadas.

No decreto 6.949, de 2009, que se refere ao direito da pessoa com deficiência, ao longo de 24 páginas, observamos que a inclusão é indicada a partir de seis trechos. Em um deles, o documento explicita em seus princípios gerais que a pessoa com deficiência deve ter "a plena e efetiva participação e inclusão na sociedade" (BRASIL, p. 3). No artigo 19, em que trata sobre vida independente e inclusão na comunidade, o decreto elucida que

[...] Os Estados Partes desta Convenção reconhecem o igual direito de todas as pessoas com deficiência de viver na comunidade, com a mesma liberdade de escolha que as demais pessoas, e tomarão medidas efetivas e apropriadas para facilitar às pessoas com deficiência o pleno gozo desse direito e sua plena inclusão e participação na comunidade. (BRASIL, p. 9).

No artigo 24 do decreto, que especifica os direitos a Educação, o documento aponta que os Estados Partes devem assegurar uma educação com "sistema educacional inclusivo em todos os níveis" (BRASIL, p. 11). Para assegurar este direito, o documento sugere que os Estados Partes realizem uma série de medidas para que haja cumprimento do direito:

[...] a) As pessoas com deficiência não sejam excluídas do sistema educacional geral sob alegação de deficiência e que as crianças com deficiência não sejam excluídas do ensino primário gratuito e compulsório ou do ensino secundário, sob alegação de deficiência; b) As pessoas com deficiência possam ter acesso ao ensino primário inclusivo, de qualidade e gratuito, e ao ensino secundário, em igualdade de condições com as demais pessoas na comunidade em que vivem; c) Adaptações razoáveis de acordo com as necessidades individuais sejam providenciadas; d) As pessoas com deficiência recebam o apoio necessário, no âmbito do sistema educacional geral, com vistas a facilitar sua efetiva educação; e) Medidas de apoio individualizadas e efetivas sejam adotadas em ambientes que maximizem o desenvolvimento acadêmico e social, de acordo com a meta de inclusão plena.

No que se refere às adaptações, o decreto deixa claro, por mais de uma vez, que adaptações razoáveis devem ser feitas para garantir a plena participação da pessoa com deficiência em diferentes atividades da vida, seja na educação, no trabalho, na saúde, na reabilitação, etc. O texto também apresenta o significado de adaptações razoáveis, que aparece ao longo da escrita do decreto. Segundo o documento, 


\begin{abstract}
"Adaptação razoável" significa as modificações e os ajustes necessários e adequados que não acarretem ônus desproporcional ou indevido, quando requeridos em cada caso, a fim de assegurar que as pessoas com deficiência possam gozar ou exercer, em igualdade de oportunidades com as demais pessoas, todos os direitos humanos e liberdades fundamentais. (BRASIL, 2009, p. 3)
\end{abstract}

Como se trata de um documento a respeito dos direitos das pessoas com deficiência, não faz menção aos serviços de atendimentos especializados e da sala regular de ensino. Como podemos observar, o documento exemplifica a inclusão de maneira mais ampla, apontando diretrizes para que se cumpra os direitos das pessoas com deficiência na sociedade como um todo (seguindo as recomendações dos acordos mundialmente firmados e aqui já enunciados).

O terceiro texto analisado foi a Resolução $n^{\circ} 4$ de 2009, que instituiu as Diretrizes Operacionais para o Atendimento Educacional Especializado na Educação Básica, modalidade Educação Especial. Logo no início da resolução, ficou explicitado que o aluno com deficiência, transtornos globais do desenvolvimento e altas habilidades/superdotação devem ser matriculados na escola de ensino comum e no AEE. Como já frisado pela PNEPEEI (BRASIL, 2008), o AEE não é substitutivo ao ensino comum. Segundo o documento, é função do AEE disponibilizar recursos de acessibilidade para o aluno com deficiência na escola,

[...] consideram-se recursos de acessibilidade na educação aqueles que asseguram condições de acesso ao currículo dos alunos com deficiência ou mobilidade reduzida, promovendo a utilização dos materiais didáticos e pedagógicos, dos espaços, dos mobiliários e equipamentos, dos sistemas de comunicação e informação, dos transportes e dos demais serviços. (BRASIL, 2009, p. 1).

Percebemos que a resolução indicou, enquanto função do AEE, elaborar recursos para a plena participação do aluno no currículo escolar. O documento não menciona, entretanto, se o currículo ou as atividades devem ser adaptadas, flexibilizadas ou diferenciadas. A Resolução (2009) também explicita qual a função do professor do AEE, sendo ele responsável pela articulação com a sala de ensino comum. No artigo 13, parágrafo sexto e oitavo, fica assim indicado:

VI - Orientar professores e famílias sobre os recursos pedagógicos e de acessibilidade utilizados pelo aluno;

VIII - estabelecer articulação com os professores da sala de aula comum, visando à disponibilização dos serviços, dos recursos pedagógicos e de acessibilidade e das estratégias que promovem a participação dos alunos nas atividades escolares. (BRASIL, 2009, p. 3)

Ao longo do texto, a resolução aponta, além das atribuições do professor do AEE, o público-alvo atendido pela Educação Especial (bem como já realizado pela PNEPEEI, BRASIL, 2008), e como o financiamento se dá, na rede pública, para estes alunos. O documento explicita ainda que é função do Projeto Político Pedagógico (PPP) das escolas (entendidas nesta dissertação como documentos curriculares das instituições), a institucionalização da oferta do AEE. Na resolução, não são encontrados termos como adaptação, flexibilização ou diferenciação.

A Resolução n 4, de 2010, que define as Diretrizes Curriculares Nacionais para a Educação Básica, menciona na Seção II, artigo 29 a Educação Especial. Segundo as Diretrizes (BRASIL, 2010, p. 10), 
A Educação Especial, como modalidade transversal a todos os níveis, etapas e modalidades de ensino, é parte integrante da educação regular, devendo ser prevista no projeto político-pedagógico da unidade escolar.

Novamente, em um texto político brasileiro, fica registrado que a Educação Especial faz parte do ensino regular, devendo as escolas, em seus currículos, contemplarem-na.

Pela primeira vez, a partir da PNEPEEI (BRASIL, 2008), um documento explicitou o conjunto de funções, tanto do professor da sala comum como do AEE. De acordo com o texto

[...] Os sistemas e as escolas devem criar condições para que o professor da classe comum possa explorar as potencialidades de todos os estudantes, adotando uma pedagogia dialógica, interativa, interdisciplinar e inclusiva e, na interface, o professor do AEE deve identificar habilidades e necessidades dos estudantes, organizar e orientar sobre os serviços e recursos pedagógicos e de acessibilidade para a participação e aprendizagem dos estudantes (BRASIL, 2010, p. 11).

Observamos novamente, de acordo com o documento curricular, que cabe ao professor do AEE organizar e orientar os serviços e recursos pedagógicos de acessibilidade. A respeito da inclusão, 0 documento aponta indicativos em quatro trechos. O primeiro diz respeito a garantia que o Estado Brasileiro deve prover ao acesso, inclusão, permanência e conclusão das crianças, jovens e adultos da Educação Básica nas instituições educacionais (BRASIL, 2010).

No segundo ponto, nas referências conceituais das diretrizes, a inclusão é mencionada para proporcionar a todos os alunos da Educação Básica "[...] I - igualdade de condições para o acesso, inclusão, permanência e sucesso na escola;" (BRASIL, 2010, p. 2). No título IV das diretrizes, no título sobre acesso e permanência para a conquista da qualidade social, fica garantido no artigo 8

A garantia de padrão de qualidade, com pleno acesso, inclusão e permanência dos sujeitos das aprendizagens na escola e seu sucesso, com redução da evasão, da retenção e da distorção de idade/ano/série, resulta na qualidade social da educação, que é uma conquista coletiva de todos os sujeitos do processo educativo.

O último ponto de inclusão do documento indica que as escolas de educação básica devem ter a inclusão como um requisito básico para a garantia da plena aprendizagem dos alunos. Referente a adaptação, adequação ou outro termo dos aqui explicitados, não foi encontrado nenhum que detalhasse como deveria ser efetivado.

Outro documento aqui listado diz respeito ao Decreto 7.611, que "dispõe sobre a educação especial, o atendimento educacional especializado e dá outras providências" (BRASIL, 2011). Bem como garante a resolução $\mathrm{n}^{\circ} 4$ de 2009, o Decreto 7.611 afirma que é dever do estado a "I - garantia de um sistema educacional inclusivo em todos os níveis, sem discriminação e com base na igualdade de oportunidades." (BRASIL, 2011, p. 1). No artigo 3, que dispõe sobre os objetivos do AEE, o Decreto reitera que faz parte das atribuições deste serviço o provimento de

[...] condições de acesso, participação e aprendizagem no ensino regular e garantir serviços de apoio especializados de acordo com as necessidades individuais dos estudantes; II - garantir a transversalidade das ações da educação especial no ensino regular; III - fomentar o desenvolvimento de recursos didáticos e pedagógicos que eliminem as barreiras no processo de ensino e aprendizagem; e IV - assegurar condições para a continuidade de estudos nos demais níveis, etapas e modalidades de ensino. (BRASIL, 2011, p. 2) 
O Decreto, no artigo 5, contempla a questão da inclusão por meio da formação de professores, gestores e outros profissionais da educação para a "elaboração, produção e distribuição de recursos educacionais para a acessibilidade” (BRASIL, 2011, p. 2).

Ao longo dos textos já citados, podemos perceber que grande parte dos registros que são feitos nesses documentos são feitos para afirmar que a educação deve garantir um sistema educacional inclusivo e a plena participação e permanência dos alunos da Educação Especial na sociedade. Realizam também uma espécie de discurso único para assegurar que as escolas devem preparar recursos pedagógicos que incluam estes alunos, para eliminar as barreiras de aprendizagem. E quais são as ditas barreiras de aprendizagem? Como garantir um sistema educacional inclusivo?

Procuramos refletir com base em autores que buscam aprofundar as questões sobre o currículo, a inclusão de alunos com deficiência no contexto escolar e as políticas curriculares.

Autoras como Lunardi-Mendes e Silva (2014) entendem que a escola que se diz contemporânea atende muitas demandas e algumas questões que deveriam ser priorizadas no cotidiano escolar acabam ficando em segundo plano, como o enfrentamento e discussão do conhecimento que é trabalhado nas salas de aulas. Segunda as autoras, a gama de políticas curriculares que a escola deve seguir/cumprir estão se preocupando cada vez mais com a performance dos alunos nas avaliações nacionais e internacionais do que com o seu desenvolvimento integral.

Conforme observamos nos textos políticos aqui citados, grande parte do texto indica o que a escola deve garantir ao aluno, etc., mas pouco se pensa nos contextos escolares para criação de determinada política. De acordo com o estudo realizado por Lunardi-Mendes e Silva (2014), os documentos curriculares da escola estão indicando aos envolvidos no contexto escolar muito mais o caminho de como fazer para trabalhar determinado conhecimento (metodologia) do que o pensamento reflexivo de "o que estamos fazendo", "porque estamos ensinando" ou se o "o conhecimento proporcionado está sendo oferecido de forma inclusiva".

Conforme o estudo realizado pelas autoras, diante de um currículo homogeneizador, que se preocupa mais com a performance e resultados do que com as relações e processos de aprendizagem dos alunos no contexto escolar, o movimento curricular como a diferenciação curricular fica restrita ao modo de "como fazer" determinada atividade (já que as políticas indicam que as escolas devem garantir a plena inclusão e a "eliminação" de barreiras), do que realmente uma mudança curricular no sentido de potencializar os diferentes ritmos de aprendizagem dos alunos. Para Lunardi-Mendes e Silva (2014, p. 10),

Tal dificuldade se alimenta a partir da interpretação de que as diferenciações/flexibilizações curriculares devem se dar pela adesão imediata, não refletida, para a qual os agentes escolares deixam de ser sujeitos em processo de aprendizagem determinados pela configuração de significados e comportamentos que elaboram de forma particular, induzidos por um contexto mais ou menos estimulado por esquemas de pensamento e ação fragmentários, carregados de mitos e preconceitos, sob o qual se assentam suas interpretações acerca da realidade.

As autoras indicam que este tipo de interpretação de movimentos como diferenciação e/ou flexibilização curricular acaba gerando um processo de diferenciação curricular negativa. Porém, as pesquisas pontuam que este tipo de prática não é culpa do professor, que está em sala atendendo a diversas demandas do contexto escolar, mas de uma política que se cria a partir de contextos ilusórios e não de contextos reais. 
Nos estudos realizados por Mesquita (2010), a partir da análise das políticas curriculares para os estudantes com necessidades educacionais especiais, a autora entende que em se tratando de inclusão, o termo adequado tanto para políticas como para os documentos escolares não estaria ligado a adaptação curricular, pois este termo se remete a homogeneização dos alunos com deficiência, oferecendo um currículo para ele se igualar aos alunos ditos "normais".

A autora defende que o movimento de diferenciação curricular poderia ser um dos modos de inclusão dos alunos com necessidades educacionais especiais, embora a autora ressalte que esta diferenciação deve ser refletida, planejada e discutida, para que não ocorra a diferenciação curricular negativa, servindo apenas para como mais um tipo de homogeneização para o aluno com deficiência.

Para Mesquita (2010, p. 313), "O ponto de partida da inclusão deve ser um currículo acessível a todos os estudantes. Nesse sentido, teria muito mais sentido falar em diferenciação do que em adaptação curricular." A autora salienta, porém, que devemos ter cuidado com as análises que são feitas por meio do currículo, das políticas e da diferenciação curricular. No artigo em que discute o processo de inclusão-exclusão escolar dos alunos com deficiência, a autora preocupa-se com a 'dita' diferenciação curricular e indaga-se se ela, da forma que hoje é realizada na escola, serve para incluir os alunos da Educação Especial nas salas de aulas, como preveem as políticas de educação inclusiva.

De acordo com a pesquisa da autora, as formas de flexibilização/diferenciação do currículo nas escolas estão sendo realizadas, no Brasil, pela inserção dos sujeitos no ambiente escolar, nos espaços individualizados de atendimento especializado, pelas classes de aceleração ou passagem automática de uma séria a outra, sem que haja real avanço na aprendizagem do sujeito com deficiência. Segundo Mesquita (2009, p. 85), "Da forma como vem sendo desenvolvida, a diferenciação curricular legitima e oculta a manutenção de uma lógica de uniformidade curricular como eventualmente a alimenta e reforça. Nesse sentido, continua excluindo."

\section{CONSIDERAÇÕES}

A partir da análise empreendida neste artigo, constatou-se que a ausência de objetividade dos textos, no que diz respeito as políticas curriculares para o público-alvo da Educação Especial, contribuem com os dissensos existente no campo e nas pesquisas científicas quando falamos dos termos discutidos. Dessa forma, fica difícil "agarrar" os sentidos intencionais das políticas com relação a esses movimentos curriculares e as interpretações feitas pelos autores locais são muito vinculadas as possiblidades dos seus contextos.

Ademais, essa ausência de objetividade ao tratar os termos adaptação, flexibilização e diferenciação, dão espaços para políticas de centralização curricular como a BNCC (Base Nacional Comum (urricular) ter um caráter prescritivo forte inclusive sobre os serviços previstos na Educação Especial, como o Atendimento Educacional Especializado.

Os documentos curriculares da área da Educação Especial precisariam explicitar a compreensão dos conceitos de adaptar, diferenciar e diferir, para efetivamente contribuir com práticas escolares mais inclusivas para o público-alvo da Educação Especial.

\section{REFERÊNCIAS}

ARANHA, M. S. F. Projeto Escola Viva: garantindo o acesso e permanência de todos os alunos na escola: necessidades educacionais especiais dos alunos. Brasília: Ministério da Educação, Secretaria de Educação Especial, 2005.

BOER, W. A. Adequações curriculares na área da deficiência intelectual: análise de uma realidade. 2012. Dissertação (Mestrado em Educação) - Universidade Federal de São Carlos. São Carlos, SP, 2012. 
BRASIL. Decreto n. ${ }^{\circ}$ 6.949, de 25 de agosto de 2009, promulga a Convenção Internacional sobre os Direitos das Pessoas com Deficiência - ONU. Diário Oficial da União, Brasília, 2009a.

BRASIL. Decreto . $^{\circ} 7.611$, de 17 de novembro de 2011. Dispõe sobre a educação especial, o atendimento educacional especializado e dá outras providências, 2011.

BRASIL. Ministério da Educação. Política Nacional de Educação Especial na Perspectiva da Educação Inclusiva. Brasília: MEC/SECADI, 2008.

BRASIL. Resolução 04, de 02 de outubro de 2009. Institui diretrizes operacionais para o atendimento educacional especializado na Educação Básica, modalidade Educação Especial, 2009b.

BRASIL. Resolução CNE/CEB n. ${ }^{\circ}$ 04, de 13 de junho de 2010. Define Diretrizes Curriculares Nacionais Gerais para Educação Básica, 2010.

CARVALHO, R. E. Escola Inclusiva: a reorganização do trabalho pedagógico. Porto Alegre: Mediação, 2008.

CORREIA, G. B. Deficiência, conhecimento e aprendizagem: Uma análise relativa à produção acadêmica sobre Educação Especial e Currículo. 2016. 187p. Dissertação (Mestrado em Educação) - Universidade Federal do Rio Grande do Sul, Porto Alegre, 2016.

FIERRO, A. Alunos com deficiência mental. In: COLL, C.; MARCHESI, A.; PALACIOS J. Desenvolvimento psicológico e educação: transtorno de desenvolvimento e necessidades educativas especiais. Porto Alegre: ArtMed Editora, 2004.

FLORO, L. F. D. Inclusão escolar, sala de recursos multifuncionais e currículo: tecendo aproximações. 2016. 306p. Dissertação (Mestrado em Educação) - Universidade de São Paulo, São Paulo, 2016.

GARCIA, R. M. C. O conceito de flexibilidade curricular nas políticas públicas de inclusão educacional. In: JESUS, D. M. et. al. Inclusão, práticas pedagógicas e trajetórias de pesquisas. Porto Alegre: Mediação, 2009, p. 11-19.

HEREDERO, E. S. A escola inclusiva e estratégias para fazer frente a ela: as adaptações curriculares. Acta Scientiarum Education. v. 32. n. 2. 2010.

LOBO, J. A. Projetos políticos pedagógicos de escolas da Rede Municipal de Ensino de Corumbá-MS: aproximações às proposições de flexibilização/adaptações curriculares. 2011. 117p. Dissertação (Mestrado em Educação). Universidade Federal do Mato Grosso do Sul, Campo Grande, 2011.

LUNARDI-MENDES, G. M.; SILVA, F. C. T. Currículo e conhecimento escolar na contemporaneidade: desafios para a escolarização de sujeitos com deficiência. Arquivos Analíticos de Políticas Educativos. v. 22. n. 80. 2014.

MELO, H. Ar. O acesso curricular para alunos(as) com deficiência intelectual na rede regular de ensino: a prática pedagógica na sala de recursos como eixo para análise. 2008. 159p. Dissertação (Mestrado em Educação). Universidade Federal do Maranhão, São Luís, 2008.

MESQUISTA, A. Currículo e educação inclusiva: as políticas curriculares nacionais. Revista Espaço do Currículo. v. 3. n. 1. 2010. 
MESQUISTA, A. Os elementos da inclusividade na prática curricular de uma professora: uma análise a partir da cultura escolar. UFPA: 2013. 174p. Tese (Doutorado em Educação) - Universidade Federal do Pará, Belém, 2013.

MESQUISTA, Amélia. Vozes ausentes: o currículo e a proposta de educação inclusiva. Revista Eletrônica de Educação. v. 3. n. 1. mai. 2009.

MESQUITA, G. O Processo de Alfabetização de uma Criança Com Deficiência Intelectual no $1^{\circ}$ Ano do Ensino Fundamental. 2015. 156p. Dissertação (Mestrado em Educação) - Universidade Federal do Espírito Santo, Vitória, 2015.

MOSCARDINI, S. F. Escolarização de alunos com deficiência intelectual em classes comuns e em salas de recursos multifuncionais. 2011. Dissertação (Mestrado em Educação) - Universidade Estadual Paulista Júlio de Mesquita Filho. Araraquara, SP, 2011.

NOVAES, M. H. Adaptação escolar: diagnóstico e orientação. Petrópolis, RJ: Vozes, 2002.

OLIVEIRA, A. A. S. Currículo e programas na área de deficiência intelectual: considerações históricas e análises críticas. In: OLIVEIRA, A. A. S.; OMOTE, S.; GIROTO, C. R. (Org.). Inclusão escolar: as contribuições da Educação Especial. São Paulo: Cultura Acadêmica Editora, Marília: Fundepe Editora, 2008, p. 111-127.

ONU. Convenção sobre os Direitos das Pessoas com Deficiência, aprovada pela Assembleia Geral da ONU em dezembro de 2006. Disponível em:

https://www.fundacaodorina.org.br/a-fundacao/deficiencia-visual/convencao-da-onu-sobre-direitos-das-p essoas-com-deficiencia/. Acesso em 8 julho de 2016.

PACHECO, José. Notas sobre diversificação/diferenciação curricular em Portugal. InterMeio: Revista do Programa de Pós-Graduação em Educação. Campo Grande: MS. v. 14. n. 28. p. 178-187. jul./dez. 2008.

ROLDÃO, Maria do Céu. Diferenciação Curricular Revisitada: conceito, discurso e práxis. Porto, PT: Porto Editora, 2003.

SACRISTÁN, Gimeno. O currículo: uma reflexão sobre a prática. Tradução Ernani F. da F. Rosa. 3. ed. Porto Alegre: ArtMed, 2000.

SANTOS, Raquel Pierini. O processo de escolarização de uma aluna com deficiência intelectual: o currículo escolar em questão. 2015. 105p. Dissertação (Mestrado em Educação) - Universidade Metodista de Piracicaba, Piracicaba, 2015.

UNESCO. Declaração de Salamanca: Sobre Princípios, Políticas e Práticas na Área das Necessidades Educativas Especiais: Salamanca: Espanha, 1994.

VALERA, Juliessa Ricce. Deficiência intelectual e adaptação curricular sob o olhar de teses e dissertações. 2015. 168p. Dissertação (Mestrado em Educação) - Universidade Estadual Paulista Júlio de Mesquita Filho, Faculdade de Ciências e Letras (Campus de Araraquara), 2015.

VIEIRA, Alexandre Braga. Currículo e educação especial: as ações a partir de diálogos cotidianos. 2012. Tese (Doutorado em Educação) - Universidade Federal do Espírito Santo, Vitória, 2012.

WCEFA. Conferência Mundial de Educação Para Todos. Declaração mundial sobre educação para todos e Plano de ação para satisfazer as necessidades básicas de aprendizagem. Jomtien, Tailândia: março de 1990. 
ISSN $1983-1579$

Doi: $10.22478 /$ ufpb.1983-1579.2019v12n3.40581

http://periodicos.ufpb.br/ojs2/index.php

ZANATA, E. M. Práticas pedagógicas inclusivas para alunos surdos numa perspectiva colaborativa. 2004. 198p. Tese (Doutorado em Educação Especial) - Universidade Federal de São Carlos, São Carlos, 2005.

Recebido em: 20/06/2018

Aceito em: 30/03/2019

Publicado em: 03/10/2019 